\title{
Development of Microcontroller ATMega128 Based Injection Molding Machines With Motor Variations
}

\author{
Izwar Lubis ${ }^{1}$, Selamat Triono ${ }^{2}$, Kasman Rukun ${ }^{3}$ \\ Universitas Negeri Medan ${ }^{1,2,3}$ \\ izwar@unimed.ac.id
}

\begin{abstract}
This research is a technology development that requires microcontroller-based innovation. The problem currently faced is developing injection molding machines by replacing the drive system in order to get maintenance costs, cheaper repairs and save electricity. The purpose of this study was to apply the microcontroller ATMega128 on a small industrial machine that is an injection molding machine using a dc motor and a stepper motor in the process. The design process starts from machine design, manufacturing of mechanical machinery, electronics and programming. Tests using a mini ammeter-D02A, digital laser infrared tachometer rpm and infrared thermometer. The results of this study adjust the character of the motor used, in accordance with the respective working principles where the stepper motor works on molding that requires accuracy of position and the dc motor works more precisely for the screw press process that does not require accurate positioning of the pressure distance, from the results of motor rpm testing the maximum stepper motor is $93.9 \mathrm{rpm}$ and the maximum DC motor is 132.3 $\mathrm{rpm}$. The result of the power produced by the injection molding machine is 509.1 watts at a temperature of $260{ }^{\circ} \mathrm{C}$, so that this injection molding machine can be used in small industries.
\end{abstract}

Keywords: Microcontroller ATMega128, DC Motor, Stepper Motor, Temperature.

\section{Introduction}

The development of the plastic goods industry in Indonesia continues to increase, both in small, medium and large industries. This development occurs because the potential consumption of plastic products is still quite large, so that it becomes an opportunity for plastic goods manufacturers to develop their businesses. The problem currently faced is developing injection molding machines by replacing the drive system in order to get maintenance costs, cheaper repairs and save electricity. There are many factors that affect the yield rate of injection products such as material characteristics, mold design, and manufacturing parameters [1]. There are different ways of molding a plastic some of them are blow molding, injection molding, rotational molding and compression molding. Each technique has their own advantages in manufacturing of specific items. Injection molding is perhaps the most common and important of all plastic processing processes. The process is extremely versatile, and can produce very complex shaped parts, with the use of multi-sided molds [2]. Injection molding control involves many aspects of machine operation and plastic behavior, most importantly their interactions. In principle, the processing pressure and temperature over time determine the quality of the printed product. The control system design must combine the logical sequence of all these basic 
functions, including injection speed (which depends on pressure), clamping and opening the mold, opening and closing the drive device, barrel temperature profile, melting temperature, mold temperature, cavity pressure, holding pressure [3].

The injection molding machine uses the microcontroller ATMega128 as a breakthrough microprocessor and microcomputer technology which is a new technology to meet market needs. Microcontroller as a new technology that is semiconductor technology with more transistor content but only requires a small space so that the microcontroller can be mass produced (in large quantities) makes the price cheaper (compared to the microprocessor). The purpose of this study is to apply the microcontroller ATMega128 on small industrial machines, one of which is injection molding machines using DC motors and stepper motors in the process. The development of small injection molding machines for forming small plastics in small scale industries has been developed by Oyetunji [4].

The development of the microcontroller ATMega128 which is applied to the injection molding machine continues to innovate to get results as needed with a small industry. Microcontroller ATMega128 is an AVR family microcontroller that has $128 \mathrm{~KB}$ of flash memory capacity. AVR (Alf and Veg's Risc Processor) is a series of 8-bit CMOS microcontrollers made by ATMEL, based on the RISC (Reduced Instruction Set Computer) architecture [5].

Toshiba DC Gearbox Motor DGM-3522-2A is one type of motor that uses a DC source as its power supply. To adjust the direction of rotation of the motor by adjusting the input polarity of the DC motor. How to regulate the rotation speed of the motor by controlling the amount of voltage entering the motor or by giving PWM (Pulse With Modulation) to the DC motor. PWM is basically turning on and off the DC motor quickly. A principle of PWM. The longer the time of his life, means the motor will spin faster. As an illustration, the period of one wave of time is fixed, which changes only the life time and the time of death.

Nema23 stepper motor JK57HS82-3004B double shaft, ATmega128 trainer uses a Nema23 stepper motor with a resolution of $1.8^{\circ}$. Nema23 is a bipolar stepper motor, so it only has 4 wires. The following is the cable configuration of the Nema23 stepper motor.

Table 1. Nema23 stepper motor cable.

\begin{tabular}{cc}
\hline Wire Color & Function \\
\hline Red & $\mathrm{A}+$ \\
Green & $\mathrm{A}-$ \\
Yellow & $\mathrm{B}+$ \\
Blue & $\mathrm{B}-$ \\
\hline
\end{tabular}

\section{Method}

The location of this research was conducted at the Mechatronics Lab, Department of Mechanical Engineering Education, Faculty of Engineering, State University of Medan. This research was carried out in 2019. The design process of the injection molding machine based on the microcontroller ATMega128 can be seen in the figure below; 


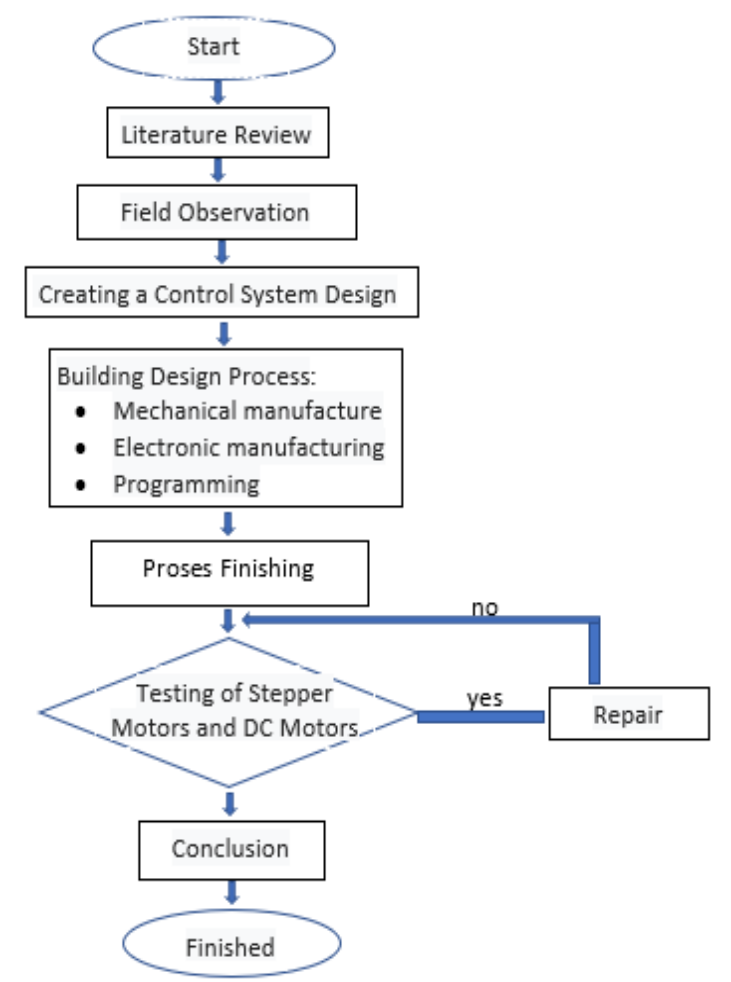

Fig. 1. Flow chart of the injection molding machine design process

Control system is a combination of several components that work together in a reciprocal manner and form a system configuration that provides a desired result [6]. The components or processes to be arranged in the injection molding machine that are designed can be seen in the image below;

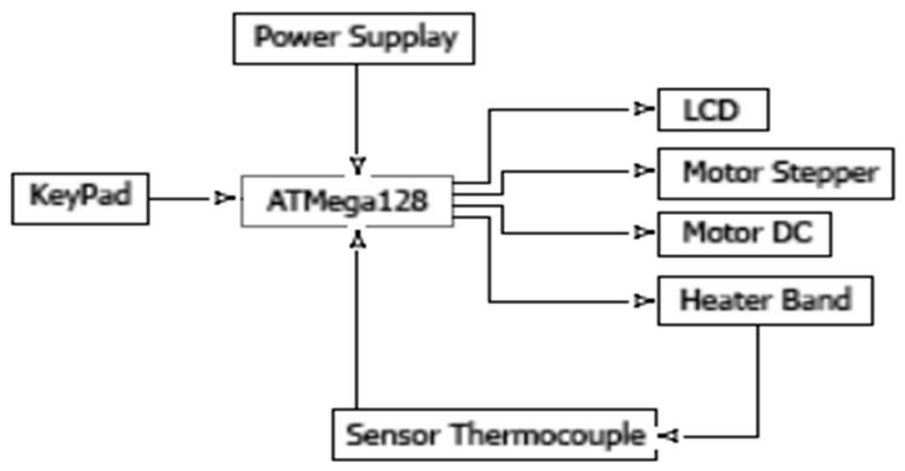

Fig. 2. The control system on an injection molding machine 


\section{Results and Discussion}

Making a design using AutoCAD software whose results can be seen in the image below;

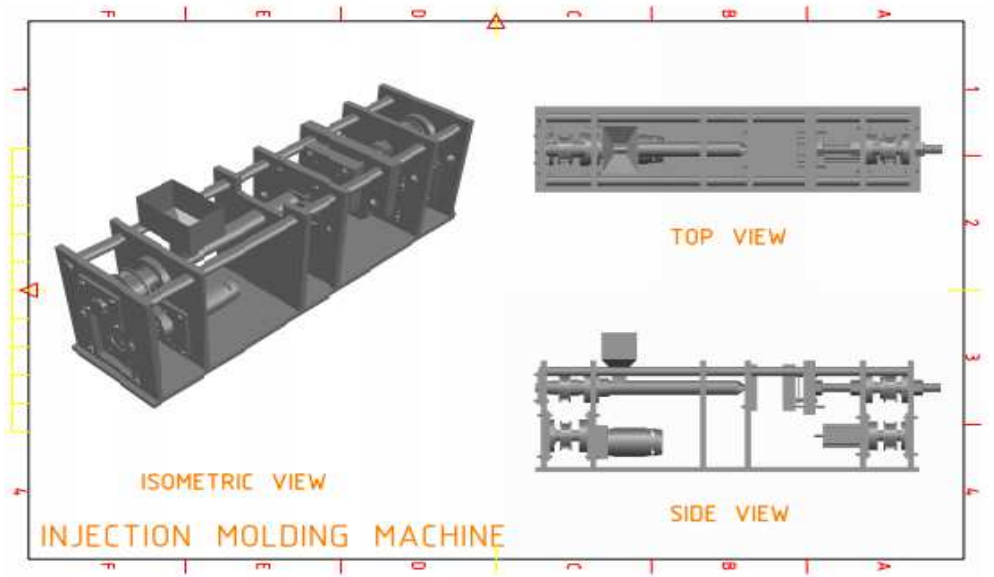

Fig. 3. Injection molding machine design

The process of making mechanical machinery is carried out through several stages starting from the selection of materials and the forming process, the results of which can be seen in the figure below;

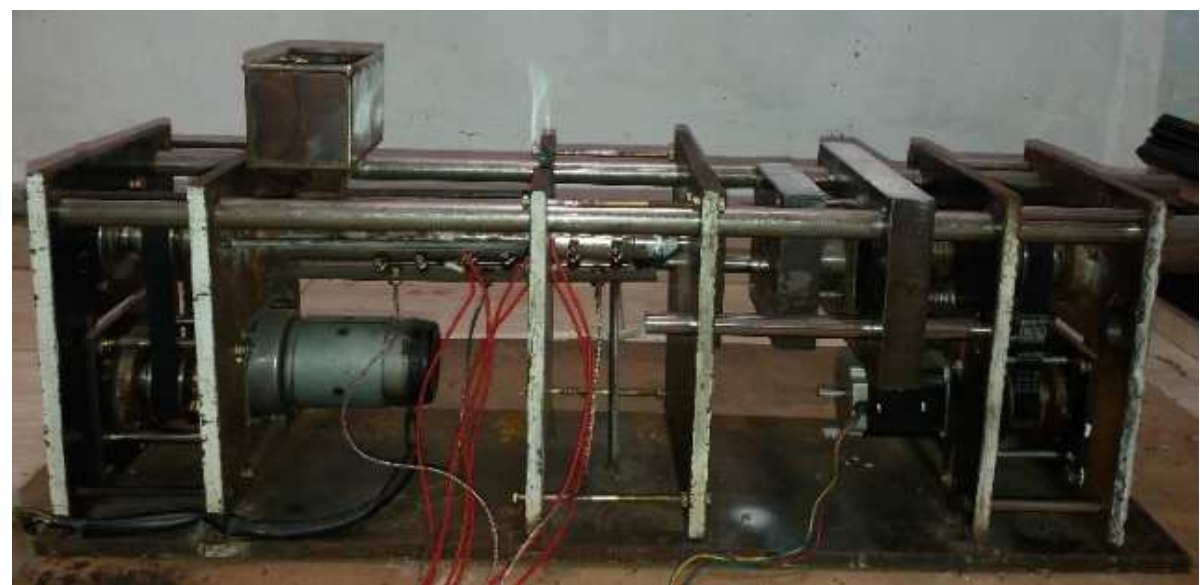

Fig. 4. Mechanical Injection Molding Machines

The electronic manufacturing process starts from designing with eagle 7.2.0 Software, by designing a schematic, board and the results of the electronic injection molding machine controller, can be seen in the picture below; 

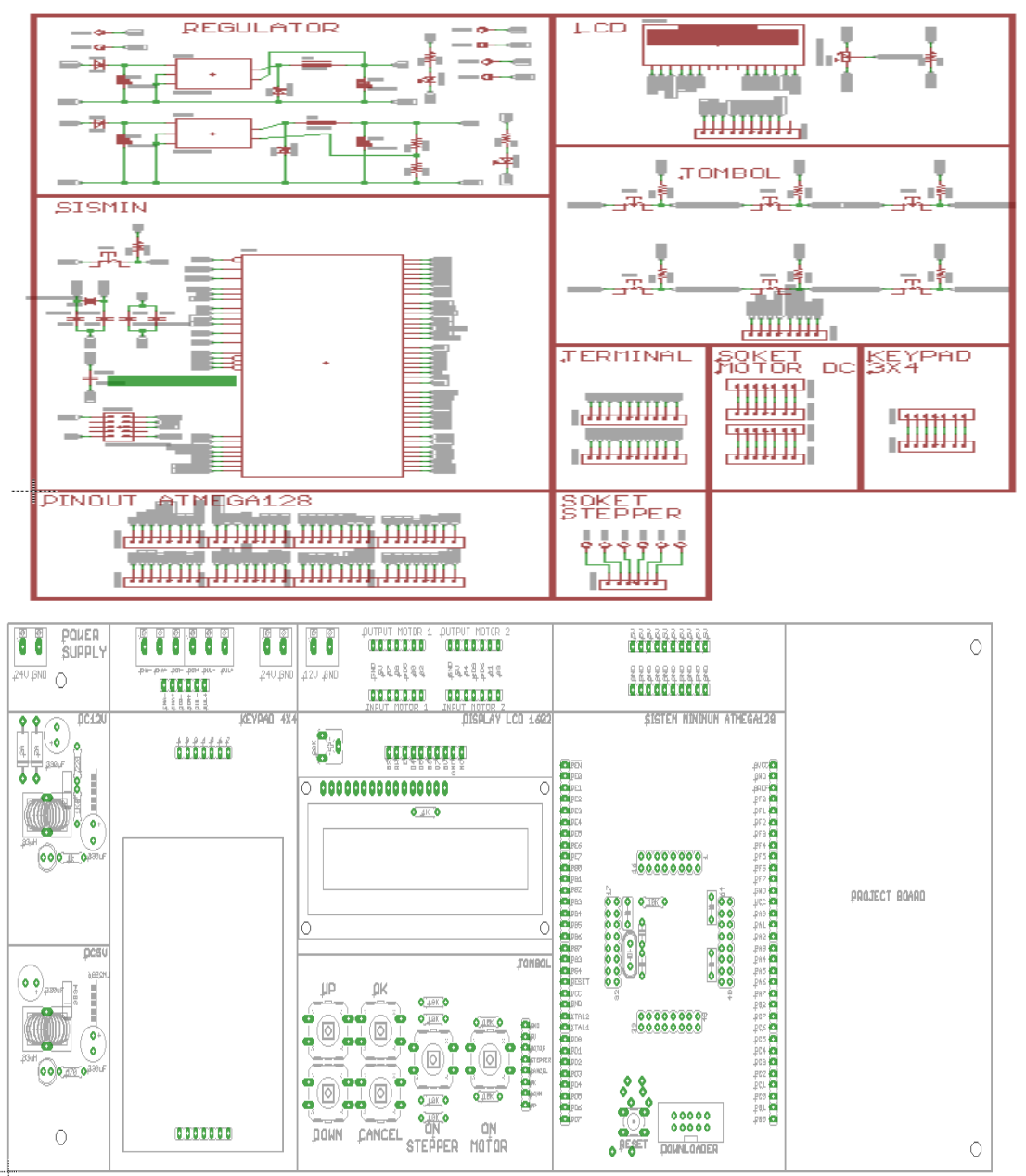

(a)

(b)

Fig. 5.(a). Schematic control of injection molding machines, (b). Board injection molding machine controls

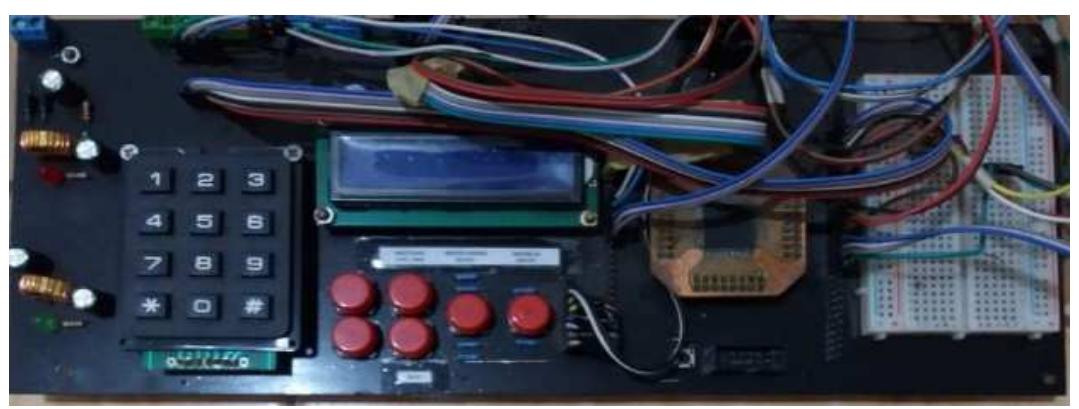

Fig. 6. Electronic control system based on the microcontroller ATMega128 


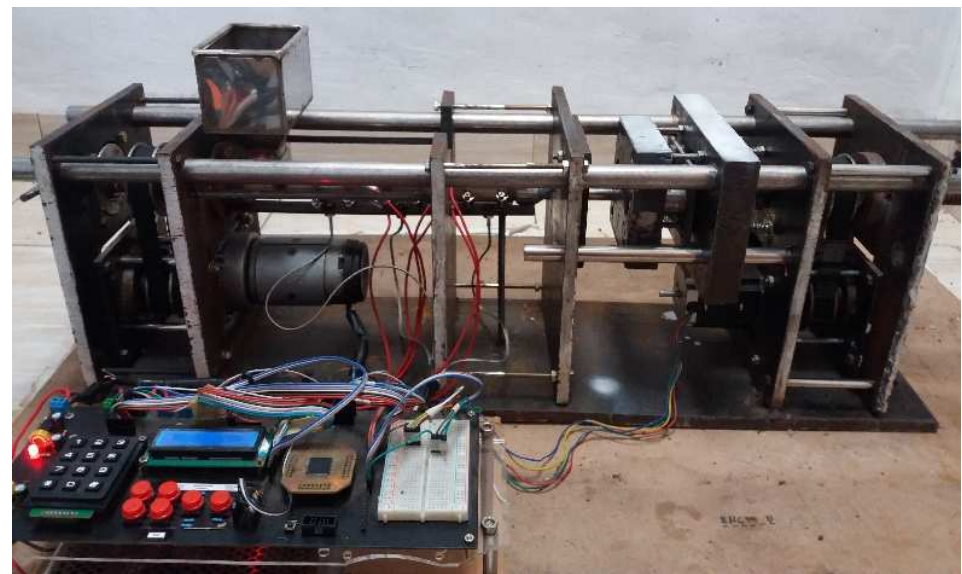

Fig. 7. Injection Molding Machine Design Results

Test equipment used in this study was the Mini ammeter-D02A, Digital laser infrared tachometer rpm and Infrared thermometer;

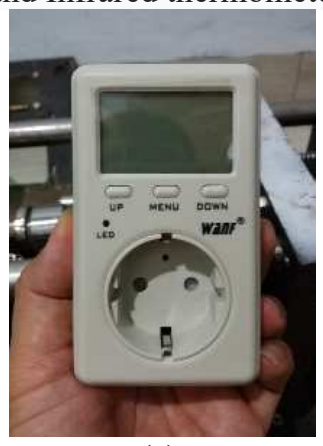

(a)

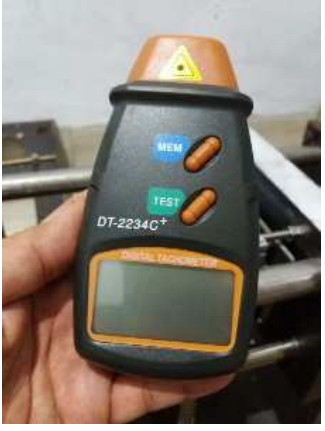

(b)

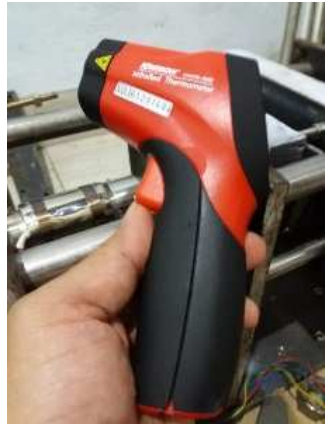

(c)

Fig. 8.(a) Mini Ammeter-D02A, (b) Digital laser infrared tachometer rpm (c) Infrared thermometer

The results of tests using Digital laser infrared tachometer rpm can be seen in Table 2 and Table 3;

Table 2. Test results of stepper motor using digital laser infrared tachometer rpm

\begin{tabular}{ccc}
\hline No & $\begin{array}{c}\text { Input } \\
\text { (rpm) }\end{array}$ & $\begin{array}{c}\text { Test Result } \\
\text { (rpm) }\end{array}$ \\
\hline 1 & 10 & 10.7 \\
2 & 20 & 20.8 \\
3 & 30 & 31.1 \\
4 & 40 & 41 \\
5 & 50 & 52.3 \\
6 & 75 & 75.3 \\
7 & 100 & 93.6 \\
8 & 150 & 93.6 \\
9 & 200 & 93.9 \\
\hline
\end{tabular}


Table 3. Testing results of DC motor using digital laser infrared tachometer rpm

\begin{tabular}{ccc}
\hline No & $\begin{array}{c}\text { Input } \\
\text { (pwm) }\end{array}$ & $\begin{array}{c}\text { Test Result } \\
\text { (rpm) }\end{array}$ \\
\hline 1 & 50 & 24.7 \\
2 & 100 & 45.9 \\
3 & 150 & 77.8 \\
4 & 200 & 98.8 \\
5 & 250 & 128 \\
6 & 300 & 129.5 \\
7 & 350 & 132.5 \\
8 & 400 & 132.1 \\
9 & 450 & 132.3 \\
\hline
\end{tabular}

The measurement results use a mini ammeter-D02A and infrared thermometer;

Table 4. Measurement results using the mini ammeter-D02A and infrared thermometer

\begin{tabular}{cccccccc}
\hline No & $\begin{array}{c}\text { Input } \\
\text { Stepper } \\
\text { Motor }\end{array}$ & $\begin{array}{c}\text { Input } \\
\text { DC } \\
\text { Motor }\end{array}$ & $\begin{array}{c}\text { Temp. } \\
\text { Input } \\
\text { Heater 1 } \\
\left({ }^{\circ} \mathbf{C}\right)\end{array}$ & $\begin{array}{c}\text { Temp. } \\
\text { Input } \\
\text { Heater 2 } \\
\left({ }^{\circ} \mathbf{C}\right)\end{array}$ & $\begin{array}{c}\text { Temp. } \\
\text { Input } \\
\text { Heater 3 } \\
\left({ }^{\circ} \mathbf{C}\right)\end{array}$ & $\begin{array}{c}\text { Temp. } \\
\text { Measurement } \\
\text { Results in } \\
\text { Cylinders } \\
\left({ }^{\circ} \mathbf{C}\right)\end{array}$ & $\begin{array}{c}\text { Measurement } \\
\text { Results } \\
\text { (Watt) }\end{array}$ \\
\hline 1 & 30 & 150 & 90 & 90 & 90 & $\mathbf{1 3 0}$ & \\
2 & 40 & 200 & 100 & 100 & 100 & $\mathbf{1 4 5}$ & $\mathbf{4 9 1 . 1}$ \\
3 & 50 & 250 & 110 & 110 & 110 & $\mathbf{1 6 0}$ & $\mathbf{5 0 0 . 7}$ \\
4 & 75 & 300 & 120 & 120 & 120 & $\mathbf{1 8 0}$ & $\mathbf{5 0 8 . 1}$ \\
5 & 100 & 350 & 150 & 150 & 150 & $\mathbf{2 6 0}$ & $\mathbf{5 0 9 . 1}$ \\
\hline
\end{tabular}

\section{Conclusion}

The results of this study to see the microcontroller ATMega128 in controlling stepper motors and DC motors work according to their functions, then the conclusions can be obtained that (1) Stepper motors and Dc motors work in accordance with the respective working principles where the stepper motors work on molding which requires accuracy of position and DC motors work more precisely for the process of screw press that does not require accuracy of the position of the compressive distance, from the results of testing the maximum stepper motor rpm $93.9 \mathrm{rpm}$ and the maximum DC motor rpm $132.3 \mathrm{rpm}$ (2) The result of the power required by the injection molding machine is 509.1 watts at a temperature of $260{ }^{\circ} \mathrm{C}$, so this injection molding machine can be used in small industries.

\section{References}

[1] Chung-Neng. Determination of Optimal Manufacturing Parameters for Injection Mold by Inverse Model Basing on MANFIS. Journal of Intelligent Learning Systems and 
Applications, 2: 28-35. doi:10.4236/jemaa.2010.21004 Published Online February 2010 (http://www.SciRP.org/journal/jilsa). (2010).

[2] Pravin P, Patil. Design And Development Of Plastic Injection Mold For Auto Component. International Journal of Advanced Engineering Research and Studies. E-ISSN2249-8974. (2014).

[3] Dominick V. Injection Molding Handbook, Springer Science+Business Media, LLC. (2000).

[4] Oyetunji, A. Development Of Small Injection Moulding Machine For Forming Small Plastic Articles For Small-Scale Industries, Department of Metallurgical and Materials Engineering. Journal of Engineering Science and Technology. Vol. 5, No. 1, 17 - 29. (2010).

[5] Atmel Rev. 8-bit Atmel Microcontroller with 128 KBytes In-System Programmable Flash 2467X-AVR-

06/11.https://www.microchip.com/wwwproducts/en/ATmega128\#datasheet-toggle

[6] Azizul E. Sistem Kontrol. UMM Press. ISBN: 978-979-796-239-5. Edisi Pertama September. (2012). 